\title{
GSTM1 gene polymorphism and the risk of colorectal cancer in a Saudi Arabian population
}

M.N. Khabaz ${ }^{1}$, T. Nedjadi ${ }^{2}$, M.A. Gari ${ }^{3}$, J.A. Al-Maghrabi ${ }^{4}$, H.M. Atta ${ }^{5}$ M. Bakarman ${ }^{6}$ and Z.J. Gazzaz ${ }^{7}$

'Department of Pathology, Rabigh Faculty of Medicine, King Abdulaziz University, Jeddah, Saudi Arabia

${ }^{2}$ King Fahd Medical Research Centre, King Abdulaziz University, Jeddah, Saudi Arabia ${ }^{3}$ Centre of Excellence in Genomic Medicine Research, King Abdulaziz University, Jeddah, Saudi Arabia

${ }^{4}$ Department of Pathology, Faculty of Medicine, King Abdulaziz University, Jeddah, Saudi Arabia

${ }^{5}$ Department of Clinical Biochemistry, Rabigh Faculty of Medicine,

King Abdulaziz University, Jeddah, Saudi Arabia

${ }^{6}$ Department of Family and Community Medicine, Rabigh Faculty of Medicine,

King Abdulaziz University, Jeddah, Saudi Arabia

${ }^{7}$ Department of Internal Medicine, Rabigh Faculty of Medicine, King Abdulaziz University, Jeddah, Saudi Arabia

Corresponding author: M.N. Khabaz

E-mail: nkhabaz@yahoo.co.uk/mnkhabaz@kau.edu.sa

Genet. Mol. Res. 15 (1): gmr.15017551

Received August 31, 2015

Accepted November 9, 2015

Published January 29, 2016

DOI http://dx.doi.org/10.4238/gmr.15017551

ABSTRACT. The enzyme glutathione S-transferase Mu 1 (GSTM1) is encoded by the GSTM1 gene. Polymorphisms in GSTM1 affect the detoxifying function of the enzyme variants. This forms the basis of the debate about the impact of the GSTM1 null/present genotype on colorectal carcinoma risk. We tested the potential influence of GSTM1 polymorphisms on the development of colorectal cancer. DNA extracted from 83 samples 
taken from patients that were previously diagnosed as having colorectal carcinoma and from 35 control subjects who did not have colorectal carcinoma were amplified. GSTM1 genotypes were determined by DNA sequencing. The current study revealed that the majority $(69 / 83,83 \%)$ of colorectal cancer cases harbored the null genotype $\left(G S T M 1^{*} 0 /{ }^{*} 0\right)$, and the remaining $14(17 \%)$ cases harbored either the GSTM1wt/wt or the GSTM1wt/*0 genotype. In contrast, among the control cases, $23(65 \%)$ had the null genotype $\left(\mathrm{GSTM}^{*}{ }^{*} /{ }^{*} 0\right)$ and $12(35 \%)$ had either the GSTM1wt/wt or the $G S T M 1 w t /{ }^{*} 0$ genotype. The current report emphasizes the impact of the GSTM1 null genotype on the increased risk of colorectal carcinoma in Saudi Arabia.

Key words: Polymorphism; GSTM1; Colorectal carcinoma

\section{INTRODUCTION}

The 2010 annual report on non-communicable diseases released by the Saudi Arabian Ministry of Health placed colorectal cancer (CRC) first among cancers affecting Saudi males and third among those affecting females. Of all recently diagnosed malignant tumors, CRCs accounted for $10.4 \%$ in the Kingdom of Saudi Arabia in 2010 (Al-Eid and Quindo, 2014). CRC development is a complicated multifactorial process, and colorectal carcinogenesis is still not well-understood (Fearon, 2011). Genetic influences play a crucial role in the carcinogenesis of many cancers including CRC (Fearon, 2011). Accumulative evidence in the field of epidemiology suggests that numerous geographical differences mirror variations in lifestyle or environmental exposure, possibly interacting with distinctions in genetic factors (Parkin et al., 1993). Polycyclic aromatic hydrocarbons (PAHs), which are present in tobacco and some dietary components, have been associated with colorectal malignancies. As glutathione S-transferases (GSTs) are engaged in the detoxification of PAHs, it has been assumed that GST genotypes may alter the risk of colorectal cancer in individuals exposed to PAHs (Hirvonen, 1995). Therefore, it has been proposed that genetic alterations in GST genes may influence susceptibility to cancer.

GST enzymes are engaged in phase II metabolic reactions and play an essential protective anticancer role via glutathione conjugation with a range of potentially cytotoxic/ genotoxic exogenous or endogenous compounds. These compounds include chemotherapeutic drugs, carcinogens (PAHs), N-nitroso compounds, benzo[a]pyrene diol epoxide-DNA adducts, environmental pollutants, products of oxidative stress such as 5-hydroxymethyluracil and DNA hydroperoxides, in addition to a wide range of xenobiotics. Consequently, the latent hazards presented by these compounds are eliminated, leaving DNA and other vital molecules unharmed and safe from adduct formation (Beckett and Hayes, 1993; Hayes and Pulford, 1995).

The major GST enzymes are GSTM1 (mu), GSTT1 (theta), and GSTP1 (pi); genes encoding these enzymes are polymorphic and are broadly expressed in gastrointestinal tissue (de Bruin et al., 2000). In humans, five genes encode the GST mu class of enzymes, and are located at chromosomal locus 1p13.3 (Pearson et al., 1993). Mu class GST genes encode cytosolic enzymes, which form a dimeric protein and show some tissue specificity in their expression (Campbell et al., 1990).

Mu class GST gene polymorphisms have been widely investigated and formerly reviewed in humans (Hayes and Pulford, 1995; Hayes and Strange, 2000). Geographic and ethnic differences affect the incidence of GSTM1 genotypes. The GSTM1*0 allele refers to a loss of the entire gene 
(the null genotype), which is the most common polymorphism of the GSTM1 gene. Individuals with the homozygous deleted allele show absence of GSTM1 enzyme activity (Tetlow et al., 2004). The incidence of the GSTM1 null genotype is $20-100 \%$, and is influenced by ethnicity (Garte et al., 2001). Individuals harboring the null genotypes have decreased carcinogen detoxification capability and are supposedly at an elevated risk of developing cancer (Hayes and Strange, 2000).

GSTM1 null genotypes are coupled with a risk of some malignancies such as lung (Seidegård et al., 1986), nasopharyngeal (Wei et al., 2013), hepatocellular (Wang et al., 2010), breast (Maugard et al., 1998), and prostate (Murata et al., 1998) cancers. In contrast, several researchers could not detect any significant relationship between GSTM1 null genotypes and cancers (Lin et al., 1998; Liu et al., 2000). It has been suggested that homozygotic deletion of the functional alleles of GSTM1 increases the risk of colorectal cancer, although many studies conducted in several populations have produced debatable outcomes. Several research groups have reported a remarkable incidence of the GSTM1 null genotype in patients with colorectal cancer (Saeed et al., 2013; Cai et al., 2014; Cong et al., 2014; Ma et al., 2014; Teng et al., 2014; Djansugurova et al., 2015), while others failed to validate this result (Hezova et al., 2012; Kassab et al., 2014; Vogtmann et al., 2014).

Recognition of predisposition factors that increase the risk of CRC if individuals are subjected to certain environmental substances may improve our knowledge of the etiology of colorectal malignancies. One way of examining the role of GSTM1 is to investigate the influence of GSTM1 polymorphisms on susceptibility to malignant colorectal tumors. Hence, this report studied the influence of the resultant genotypes of GSTM1 polymorphism and the status of colorectal cancer risk.

\section{MATERIAL AND METHODS}

Paraffin-embedded tissue samples from 83 cases of previously diagnosed colorectal cancer were analyzed in this study, in addition to 35 samples of non-cancerous colon tissue as a control group. The patients who participated in this study underwent colorectal tumor resection with regional lymph node dissection at King Abdulaziz University Hospital. Clinical data (gender, age, type of carcinoma, size, and grade of carcinoma) and tissue samples were collected by the Pathology Department of King Abdulaziz University. All cases with familial history of colorectal cancer or those who had received radiation therapy or chemotherapy were excluded from this study. All samples were stored at room temperature. The control group of tissues was obtained from patients who were biopsied for non-cancerous conditions (including adenoma and polyps), as well as nearby normal mucosa and distant surgical margins. The control population comprised 15 (43\%) females and 20 (57\%) males. The mean age was 56.7 years, and the age range was $28-87$ years. All blocks of non-cancerous control and tumor tissues were serially sectioned and used in the present study.

\section{DNA isolation}

Paraffin-embedded tissue samples were used to extract genomic DNA. A QIAamp DNA FFPE Kit (Qiagen, Germany) was used in accordance with manufacturer instructions. Purified DNA was eluted in $50 \mu \mathrm{L}$ elution buffer and stored at $-40^{\circ} \mathrm{C}$. The purity and concentration of the isolated DNA were analyzed using a NanoDrop 2000 UV-VIS spectrophotometer (Thermo Scientific, USA). 


\section{GSTM1 genotyping}

Genotyping for the recognition of GSTM1 polymorphisms in colorectal cancer was performed using a SYBR Green commercial polymerase chain reaction (PCR) kit (Qiagen) in accordance with the manufacturer instructions. Approximately $200 \mathrm{ng}$ DNA was amplified in an overall volume of $25 \mu \mathrm{L} /$ reaction. We used GSTM1 oligonucleotide primers (forward: 5'-CTGCCCTACTTGATTGATGGG-3'; reverse: 5'-CTGGATTGTAGCAGATCATGC-3') from MWGBiotech (Ebersberg, Germany) to amplify the GSTM1 fragments. The PCR was performed using a Thermal Cycler 480 (Applied Biosystems, USA) apparatus. The PCR regimen comprised: an initial denaturation at $94^{\circ} \mathrm{C}$ for $15 \mathrm{~min}$; followed by 35 cycles of denaturation at $94^{\circ} \mathrm{C}$ for 1 min, annealing at $57^{\circ} \mathrm{C}$ for $1 \mathrm{~min}$, and extension at $74^{\circ} \mathrm{C}$ for $1 \mathrm{~min}$; and a final extension at $72^{\circ} \mathrm{C}$ for $10 \mathrm{~min}$. The PCR products were examined by $1 \%$ agarose gel electrophoresis and visualized using a Syngene UV transilluminator.

\section{DNA sequencing}

A 3500 Genetic Analyzer and a BigDye Terminator v3.1 sequencing kit (Applied Biosystems) were used to sequence the amplified PCR products by following the manufacturer protocol. The resulting sequence data were investigated using the Applied Biosystems sequence analysis software (v. 5.4).

\section{Statistical analyses}

Analyses of the results were completed using SPSS version 20 and the chi-square test to establish any significant differences in polymorphism incidence between the colorectal cancer cases and the control group. Calculation of statistics was performed based on $95 \%$ confidence intervals.

\section{RESULTS}

Eighty-three colorectal cancer cases were revised. The mean age of the cases was 57.8 \pm 12.8 years (range $22-94$ years), with a slight preponderance of females $(45 ; 54.2 \%)$. More than one-third of the tumors (38.55\%) were well differentiated, $48.2 \%$ were moderately differentiated, and only $13.25 \%$ were poorly differentiated. Moderately differentiated tumors were more frequent among males (52.6\%) compared with females (44.4\%), and poorly differentiated tumors, especially with mucinous or with signet ring cell differentiation, were mostly recorded among females (Table 1). Using a modified Dukes' grading system, $1.2,2.4,55.5,34.9$, and $6 \%$ of the cancer cases were categorized as grades A, B1, B2, C2, and D, respectively. Almost two-thirds (66.7\%) of female tumors were graded B2 as opposed to $42.1 \%$ among males, whereas grade $\mathrm{C} 2$ accounted for 47.4 and $24.4 \%$ among male and female tumors, respectively (Table 1). The most common anatomic sites of the tumors were, in descending order, the ascending colon (21.69\%), the sigmoid colon $(20.48 \%)$, the rectum $(18.08 \%)$, the descending colon $(15.66 \%)$, and the rectosigmoid colon $(14.45 \%)$; and the least common sites $(4.82 \%)$ were the transverse colon and cecum. Colorectal cancer was almost equally distributed in both genders regarding sites except for the rectum where the tumors occurred $10 \%$ more frequently in males than in females. At the time of surgical removal of colorectal tumors, lymph nodes were found to be involved in more than one-third of the tumor cases $(38.6 \%)$. The average size of the tumor was $5.0 \pm 2.6 \mathrm{~cm}$, and the size range was $0.6-12 \mathrm{~cm}$ 
(Table 1). However, there were no statistically significant differences between the clinical data for the tumors in the male and female populations $(P<0.05)$ (Table 1).

Table 1. Clinicopathological characteristics of patients with colorectal cancer.

\begin{tabular}{|c|c|c|c|c|c|c|c|}
\hline \multirow{2}{*}{ Characteristics } & & \multicolumn{2}{|c|}{ All patients } & \multicolumn{2}{|c|}{ Female } & \multicolumn{2}{|c|}{ Male } \\
\hline & & No. & $\%$ & No. & $\%$ & No. & $\%$ \\
\hline Total cases & & 83 & & 45 & 54.2 & 38 & 45.8 \\
\hline \multicolumn{8}{|l|}{ Age } \\
\hline & $<40$ & 6 & 7.23 & 5 & 11.11 & 1 & 2.6 \\
\hline & $40-49$ & 12 & 14.45 & 6 & 13.3 & 6 & 15.8 \\
\hline & $50-59$ & 28 & 33.74 & 13 & 28.8 & 15 & 39.5 \\
\hline & $60-69$ & 23 & 27.72 & 12 & 26.6 & 11 & 28.9 \\
\hline & $>70$ & 14 & 15.66 & 9 & 20 & 5 & 13.2 \\
\hline Average age & $57.8(22-94)$ & & & & & & \\
\hline \multicolumn{8}{|l|}{ Tumor location } \\
\hline & Ascending colon & 18 & 21.69 & 11 & 24.4 & 7 & 18.4 \\
\hline & Transverse colon & 4 & 4.82 & 3 & $6 . .6$ & 1 & 2.6 \\
\hline & Descending colon & 13 & 15.66 & 7 & 15.5 & 6 & 15.78 \\
\hline & Rectum & 15 & 18.08 & 6 & 13.3 & 9 & 23.68 \\
\hline & Rectosigmoid colon & 12 & 14.45 & 7 & 15.5 & 5 & 13.15 \\
\hline & Sigmoid colon & 17 & 20.48 & 9 & 20 & 8 & 21.05 \\
\hline & Cecum & 4 & 4.82 & 2 & 4.4 & 2 & 5.26 \\
\hline $\begin{array}{l}\text { Average size of } \\
\text { tumor }\end{array}$ & $5 \mathrm{~cm}(0.6-12)$ & & & & & & \\
\hline \multicolumn{8}{|l|}{$\begin{array}{l}\text { Lymph node } \\
\text { involvement }\end{array}$} \\
\hline & Yes & 32 & 38.6 & 15 & 33.3 & 17 & 44.7 \\
\hline & No & 51 & 61.4 & 30 & 66.7 & 21 & 55.3 \\
\hline \multicolumn{8}{|l|}{$\begin{array}{l}\text { Tumor } \\
\text { differentiation }\end{array}$} \\
\hline & Good with/without mucin & 32 & 38.55 & 17 & 37.8 & 15 & 39.4 \\
\hline & $\begin{array}{l}\text { Moderate with/without } \\
\text { mucin }\end{array}$ & 40 & 48.2 & 20 & 44.4 & 20 & 52.6 \\
\hline & $\begin{array}{l}\text { Poor with/without mucin } \\
\text { or signet ring cells }\end{array}$ & 11 & 13.25 & 8 & 17.8 & 3 & 7.9 \\
\hline \multicolumn{8}{|l|}{$\begin{array}{l}\text { Dukes' } \\
\text { system }\end{array}$} \\
\hline & $\mathrm{A}$ & 1 & 1.2 & 0 & 0 & 1 & 2.6 \\
\hline & B1 & 2 & 2.4 & 0 & 0 & 2 & 5.3 \\
\hline & $\mathrm{B} 2$ & 46 & 55.5 & 30 & 66.7 & 16 & 42.1 \\
\hline & $\mathrm{C} 2$ & 29 & 34.9 & 11 & 24.4 & 18 & 47.4 \\
\hline & $\mathrm{D}$ & 5 & 6 & 4 & 8.9 & 1 & 2.6 \\
\hline
\end{tabular}


PCR and gene sequencing assays were performed to test the effect of the GSTM1 polymorphisms on susceptibility to colorectal malignancy. Our results (Table 2 ) showed that the majority of colorectal cancer cases $(69,83 \%)$ were of the null genotype $\left(G S T M 1^{*} 0 /{ }^{*} 0\right)$, and the remaining cases $(14,17 \%)$ were either of the GSTM1wt/wt or GSTM1wt/*0 genotypes (wt = wild-type).

The incidence of the null genotype in the current study was higher than that in similar studies that reported significant results (Table 3). However, $23(65 \%)$ and $12(35 \%)$ of the control cases were of the null genotype and the GSTM1wt/wt or GSTM1wt/*0 genotype, respectively. The results showed a significant association between deletion of the GSTM1 gene and colorectal malignancies $[\mathrm{P}$ value (two sided) $=0.03706$; odds ratio $=2.571$ with $95 \% \mathrm{Cl}=1.041-6.35]($ Table 2). However, no associations were found between the incidence of GSTM1 genotypes and the clinical and histopathological features (gender, age, site, grade, type, and lymph node metastases) of the tumors (Table 1).

Table 2. GSTM1 genotypes observed in colorectal cancer cases and controls.

\begin{tabular}{l|c|c|c|c|c}
\hline \multirow{2}{*}{ GSTP1 genotypes } & \multicolumn{2}{|c|}{ Cancer cases } & \multicolumn{2}{c|}{ Controls } & \multirow{2}{*}{$P$} \\
\cline { 2 - 5 } & Total & $\%$ & Total & $\%$ & \\
\hline Present & 14 & 17 & 12 & 35 & \multirow{2}{*}{0.03706} \\
\hline Null & 69 & 83 & 23 & 65 & \\
\hline Total & 83 & 100 & 35 & 100 & \\
\hline
\end{tabular}

$\mathrm{P}=$ Comparison between the GSTM1 deletion and non-deletion groups.

\section{DISCUSSION}

Colon tissues express GSTM1 at significant levels. Therefore, any modification in the phenotype may have a considerable influence on susceptibility to colorectal cancer, and GSTM1 in particular has been reported to contribute to the deactivation of mutagenic and carcinogenic heterocyclic amines (Beckett and Hayes, 1993; Hayes and Pulford, 1995).

The GSTM1 gene is known to be highly polymorphic. GSTM1 gene polymorphisms may exert an effect on the functioning of enzymes encoded by this gene through the change in both gene expression level and the activity of the protein itself. Thus, GSTM1 has an influence on the detoxification of carcinogens, and consequently, the level of DNA damage; in this way, an individual's susceptibility to toxins and carcinogens can vary owing to genetic variations that also affect the toxicity and effectiveness of particular drugs (Gong et al., 2012). The polymorphism of the GSTM1 gene observed in the human population comprises a hereditary homozygous deletion (null/null), a deletion of a gene fragment, resulting in a deficiency in the protein product, which is related to the total loss of enzymatic activity (Gong et al., 2012). The GSTM1 null genotype seems to be related to a low capacity for detoxification of selected xenobiotics and a reduced capability for controlling oxidative stress, which is equivalent to the damage to the cell caused by free radical activity (Wei et al., 2012). Null genotypes of this mu class gene have been associated with larger numbers of malignant tumors, probably due to an augmented susceptibility to carcinogens and environmental toxins (Procopciuc and Osian, 2014).

Many studies have assessed the possibility of colorectal cancer in individuals with the null 
genotype of GSTM1; nevertheless, the outcomes are quite debatable (Hezova et al., 2012; Cai et al., 2014; Kassab et al., 2014; Procopciuc and Osian, 2014; Teng et al., 2014; Djansugurova et al., 2015). The current paper describes GSTM1 genotypes and the impact of GSTM1 polymorphism on susceptibility to colorectal malignancies in the tested Saudi population. Despite the small sample size in the current study, our results regarding the incidence of the genotypes of GSTM1 polymorphism in the 35 controls were almost in agreement with the results of other studies from different parts of the world (van der Logt et al., 2004; Kassab et al., 2014). The slight differences observed were shown to be insignificant.

In respect of the risk of CRC, there are inconsistent reports regarding the impact of GSTM1 polymorphism on CRC susceptibility. Many studies (Houlston and Tomlinson, 2001; van der Logt et al., 2004; Hezova et al., 2012; Kassab et al., 2014) have shown that a relationship between GSTM1 polymorphism and colorectal tumors does not exist. In contrast, the current study, which recruited a comparatively small number of controls and CRC cases, supports the idea that homozygous and heterozygous wild-type allele genotypes of GSTM1 are likely to protect against colorectal malignant tumors. Furthermore, GSTM1 null genotype carriers are at a greater risk of developing colorectal malignancies. The results of this study are in agreement with those of numerous studies that have reported a significant effect of the GSTM1 null genotype on susceptibility to colorectal cancer (Sachse et al., 2002; Huang et al., 2006; Csejtei et al., 2008; Hlavata et al., 2010; Cai et al., 2014; Teng et al., 2014). The incidence of the null genotype in the current study was higher than that in similar studies that reported significant results (Table 3 ).

Table 3. Percentage of colorectal cancer cases harboring the GSTM1 null genotype that have been reported in the literature.

\begin{tabular}{l|c|c|c|c|c|c|c|c|c}
\hline Authors & $\begin{array}{c}\text { Djansugurova } \\
\text { et al. (2015) }\end{array}$ & $\begin{array}{c}\text { Cong } \\
\text { et al. } \\
(2014)\end{array}$ & $\begin{array}{c}\text { Sachse } \\
\text { et al. } \\
(2002)\end{array}$ & $\begin{array}{c}\text { Hlavata } \\
\text { et al. } \\
(2010)\end{array}$ & $\begin{array}{c}\text { Csejtei } \\
\text { et al. } \\
(2008)\end{array}$ & $\begin{array}{c}\text { Huang } \\
\text { et al. } \\
(2006)\end{array}$ & $\begin{array}{c}\text { Aghajany-Nasab } \\
\text { et al. (2011) }\end{array}$ & $\begin{array}{c}\text { Darazy } \\
\text { et al. } \\
(2011)\end{array}$ & $\begin{array}{c}\text { Current } \\
\text { study }\end{array}$ \\
\hline $\begin{array}{l}\text { GSTM1 null } \\
\text { genotype } \\
\text { percentage }\end{array}$ & 50.20 & 53.8 & 58 & 53.90 & 58.80 & 57.10 & 71.80 & 43.90 & 83 \\
\hline
\end{tabular}

Furthermore, in India, a study that included more than 300 patients with gastrointestinal cancer confirmed the association between the GSTM1 null genotype and elevated risk of rectal carcinoma. In addition, it has been suggested that the concomitance of polymorphisms in three genes, GSTM1, GSTT1, and GSTP1, may be crucial in the development of colorectal malignancies in the Hindu population (Wang et al., 2011). A further study conducted in Iran indicated that individuals aged over 60 years, harboring the GSTM1 null genotype, were predisposed to development of CRC (AghajanyNasab et al., 2011). In a Lebanese population, an increased risk of gastric and colorectal malignancies was found in individuals with the null genotype. The researchers stated that these findings confirm the outcomes of similar studies conducted on a Caucasian population (Darazy et al., 2011).

However, bearing in mind the heterogeneity of mutagenic and carcinogenic substances, as well as the complexity of xenobiotic metabolic reactions, larger comprehensive research projects are essential for evaluating genetic predisposition to colorectal cancer. Additionally, future studies should investigate the interaction between different environmental exposures and a wide range of high- or low-penetrance genes in addition to GSTM1. In general, this study confirms the suggestions of previous studies regarding the consequences of GSTM1 polymorphisms and susceptibility to colorectal cancer. Furthermore, this research has demonstrated a convincing association between GSTM1 polymorphism and colorectal cancer risk. 


\section{Conflicts of interest}

The authors declare no conflict of interest.

\section{ACKNOWLEDGMENTS}

Research supported by the Deanship of Scientific Research (DSR), King Abdulaziz University (KAU), Jeddah, under grant \#459/828/1432. The authors thank DSR for technical and financial support. The authors would also like to acknowledge the support of all administrative and technical staff at the King Fahd Center for Medical Research.

\section{REFERENCES}

Aghajany-Nasab M, Panjehpour M, Samiee SM, Rahimi F, et al. (2011). Glutathione S-transferase mu gene variants and colorectal cancer development - use of sequence-specific probes for an Iranian population. Asian Pac. J. Cancer Prev. 12: 1511-1515.

Al-Eid HS and Quindo MA (2014). Cancer Incidence Report, Saudi Arabia 2010, Kingdom of Saudi Arabia Ministry of Health Saudi Cancer Registry. http://www.chs.gov.sa/Ar/mediacenter/NewsLetter/2010\%20Report\%20(1).pdf. Accessed October 20, 2015.

Beckett GJ and Hayes JD (1993). Glutathione S-transferases: biomedical applications. Adv. Clin. Chem. 30: 281-380. http:// dx.doi.org/10.1016/S0065-2423(08)60198-5

Cai X, Yang L, Chen H and Wang C (2014). An updated meta-analysis of the association between GSTM1 polymorphism and colorectal cancer in Asians. Tumour Biol. 35: 949-953. http://dx.doi.org/10.1007/s13277-013-1125-0

Campbell E, Takahashi Y, Abramovitz M, Peretz M, et al. (1990). A distinct human testis and brain mu-class glutathione S-transferase. Molecular cloning and characterization of a form present even in individuals lacking hepatic type mu isoenzymes. J. Biol. Chem. 265: 9188-9193.

Cong N, Liu L, Xie Y, Shao W, et al. (2014). Association between glutathione S-transferase T1, M1, and P1 genotypes and the risk of colorectal cancer. J. Korean Med. Sci. 29: 1488-1492. http://dx.doi.org/10.3346/jkms.2014.29.11.1488

Csejtei A, Tibold A, Varga Z, Koltai K, et al. (2008). GSTM, GSTT and p53 polymorphisms as modifiers of clinical outcome in colorectal cancer. Anticancer Res. 28 (3B): 1917-1922.

Darazy M, Balbaa M, Mugharbil A, Saeed H, et al. (2011). CYP1A1, CYP2E1, and GSTM1 gene polymorphisms and susceptibility to colorectal and gastric cancer among Lebanese. Genet. Test. Mol. Biomarkers 15: 423-429. http://dx.doi. org/10.1089/gtmb.2010.0206

de Bruin WC, Wagenmans MJ and Peters WH (2000). Expression of glutathione S-transferase alpha, P1-1 and T1-1 in the human gastrointestinal tract. Jpn. J. Cancer Res. 91: 310-316. http://dx.doi.org/10.1111/j.1349-7006.2000.tb00946.x

Djansugurova L, Zhunussova G, Khussainova E, Iksan O, et al. (2015). Association of DCC, MLH1, GSTT1, GSTM1, and TP53 gene polymorphisms with colorectal cancer in Kazakhstan. Tumour Biol. 36: 279-289. http://dx.doi.org/10.1007/ $\underline{\text { s13277-014-2641-2 }}$

Fearon ER (2011). Molecular genetics of colorectal cancer. Annu. Rev. Pathol. 6: 479-507. http://dx.doi.org/10.1146/annurevpathol-011110-130235

Garte S, Gaspari L, Alexandrie AK, Ambrosone C, et al. (2001). Metabolic gene polymorphism frequencies in control populations. Cancer Epidemiol. Biomarkers Prev. 10: 1239-1248.

Gong M, Dong W, Shi Z, Xu Y, et al. (2012). Genetic polymorphisms of GSTM1, GSTT1, and GSTP1 with prostate cancer risk: a meta-analysis of 57 studies. PLoS One 7: e50587. http://dx.doi.org/10.1371/journal.pone.0050587

Hayes JD and Pulford DJ (1995). The glutathione S-transferase supergene family: regulation of GST and the contribution of the isoenzymes to cancer chemoprotection and drug resistance. Crit. Rev. Biochem. Mol. Biol. 30: 445-600. http://dx.doi. org/10.3109/10409239509083491

Hayes JD and Strange RC (2000). Glutathione S-transferase polymorphisms and their biological consequences. Pharmacology 61: 154-166. http://dx.doi.org/10.1159/000028396

Hezova R, Bienertova-Vasku J, Sachlova M, Brezkova V, et al. (2012). Common polymorphisms in GSTM1, GSTT1, GSTP1, GSTA1 and susceptibility to colorectal cancer in the Central European population. Eur. J. Med. Res. 17: 17. http://dx.doi. org/10.1186/2047-783X-17-17

Hirvonen A (1995). Genetic factors in individual responses to environmental exposures. J. Occup. Environ. Med. $37: 37-43$. 
http://dx.doi.org/10.1097/00043764-199501000-00006

Hlavata I, Vrana D, Smerhovsky Z, Pardini B, et al. (2010). Association between exposure-relevant polymorphisms in CYP1B1, EPHX1, NQO1, GSTM1, GSTP1 and GSTT1 and risk of colorectal cancer in a Czech population. Oncol. Rep. 24: 13471353.

Houlston RS and Tomlinson IP (2001). Polymorphisms and colorectal tumor risk. Gastroenterology 121: 282-301. http://dx.doi. org/10.1053/gast.2001.26265

Huang K, Sandler RS, Millikan RC, Schroeder JC, et al. (2006). GSTM1 and GSTT1 polymorphisms, cigarette smoking, and risk of colon cancer: a population-based case-control study in North Carolina (United States). Cancer Causes Control 17: 385-394. http://dx.doi.org/10.1007/s10552-005-0424-1

Kassab A, Msolly A, Lakhdar R, Gharbi O, et al. (2014). Polymorphisms of glutathione-S-transferases M1, T1, P1 and susceptibility to colorectal cancer in a sample of the Tunisian population. Med. Oncol. 31: 760. http://dx.doi.org/10.1007/ s12032-013-0760-z

Lin DX, Tang YM, Peng Q, Lu SX, et al. (1998). Susceptibility to esophageal cancer and genetic polymorphisms in glutathione S-transferases T1, P1, and M1 and cytochrome P450 2E1. Cancer Epidemiol. Biomarkers Prev. 7: 1013-1018.

Liu G, Ghadirian P, Vesprini D, Hamel N, et al. (2000). Polymorphisms in GSTM1, GSTT1 and CYP1A1 and risk of pancreatic adenocarcinoma. Br. J. Cancer 82: 1646-1649.

Ma X, Zhang B and Zheng W (2014). Genetic variants associated with colorectal cancer risk: comprehensive research synopsis, meta-analysis, and epidemiological evidence. Gut 63: 326-336.

Maugard CM, Charrier J and Bignon YJ (1998). Allelic deletion at glutathione S-transferase M1 locus and its association with breast cancer susceptibility. Chem. Biol. Interact. 111-112: 365-375. http://dx.doi.org/10.1016/S0009-2797(97)00173-7

Murata M, Shiraishi T, Fukutome K, Watanabe M, et al. (1998). Cytochrome P4501A1 and glutathione S-transferase M1 genotypes as risk factors for prostate cancer in Japan. Jpn. J. Clin. Oncol. 28: 657-660. http://dx.doi.org/10.1093/ijco/28.11.657

Parkin DM, Pisani P and Ferlay J (1993). Estimates of the worldwide incidence of eighteen major cancers in 1985. Int. J. Cancer 54: 594-606. http://dx.doi.org/10.1002/ijc.2910540413

Pearson WR, Vorachek WR, Xu SJ, Berger R, et al. (1993). Identification of class-mu glutathione transferase genes GSTM1GSTM5 on human chromosome 1p13. Am. J. Hum. Genet. 53: 220-233.

Procopciuc LM and Osian G (2014). GSTM1-null genotype as a risk factor for sporadic colorectal cancer in a Romanian population. Association with the NAT2-rapid-acetylator phenotype and exposure to environmental factors. Cancer Invest. 32: 53-62. http://dx.doi.org/10.3109/07357907.2013.867972

Sachse C, Smith G, Wilkie MJ, Barrett JH, et al.; Colorectal Cancer Study Group (2002). A pharmacogenetic study to investigate the role of dietary carcinogens in the etiology of colorectal cancer. Carcinogenesis 23: 1839-1849. http:// dx.doi.org/10.1093/carcin/23.11.1839

Saeed HM, Alanazi MS, Nounou HA, Salaby MA, et al. (2013). Cytochrome P450 1A1, $2 E 1$ and GSTM1 gene polymorphisms and susceptibility to colorectal cancer in the Saudi population. Asian Pac. J. Cancer Prev. 14: 3761-3768. http://dx.doi. org/10.7314/APJCP.2013.14.6.3761

Seidegård J, Pero RW, Miller DG and Beattie EJ (1986). A glutathione transferase in human leukocytes as a marker for the susceptibility to lung cancer. Carcinogenesis 7: 751-753. http://dx.doi.org/10.1093/carcin/7.5.751

Teng Z, Wang L, Zhang J, Cai S, et al. (2014). Glutathione S-transferase M1 polymorphism and colorectal cancer risk in Chinese population. Tumour Biol. 35: 2117-2121. http://dx.doi.org/10.1007/s13277-013-1281-2

Tetlow N, Robinson A, Mantle T and Board P (2004). Polymorphism of human mu class glutathione transferases. Pharmacogenetics 14: 359-368. http://dx.doi.org/10.1097/00008571-200406000-00005

van der Logt EM, Bergevoet SM, Roelofs HM, van Hooijdonk Z, et al. (2004). Genetic polymorphisms in UDPglucuronosyltransferases and glutathione S-transferases and colorectal cancer risk. Carcinogenesis 25: 2407-2415. http://dx.doi.org/10.1093/carcin/bgh251

Vogtmann E, Xiang YB, Li HL, Cai Q, et al. (2014). Cruciferous vegetables, glutathione S-transferase polymorphisms, and the risk of colorectal cancer among Chinese men. Ann. Epidemiol. 24: 44-49. http://dx.doi.org/10.1016/j.annepidem.2013.10.003

Wang B, Huang G, Wang D, Li A, et al. (2010). Null genotypes of GSTM1 and GSTT1 contribute to hepatocellular carcinoma risk: evidence from an updated meta-analysis. J. Hepatol. 53: 508-518. http://dx.doi.org/10.1016/j.jhep.2010.03.026

Wang J, Jiang J, Zhao Y, Gajalakshmi V, et al. (2011). Genetic polymorphisms of glutathione S-transferase genes and susceptibility to colorectal cancer: a case-control study in an Indian population. Cancer Epidemiol. 35: 66-72. http:// dx.doi.org/10.1016/j.canep.2010.07.003

Wei B, Xu Z, Zhou Y, Ruan J, et al. (2012). Association of GSTM1 null allele with prostate cancer risk: evidence from 36 casecontrol studies. PLoS One 7: e46982. http://dx.doi.org/10.1371/journal.pone.0046982

Wei Y, Zhou T, Lin H, Sun M, et al. (2013). Significant associations between GSTM1/GSTT1 polymorphisms and nasopharyngeal cancer risk. Tumour Biol. 34: 887-894. http://dx.doi.org/10.1007/s13277-012-0623-9 